\title{
Comparison of Minimally Invasive Treatment Methods for Urinary Stones: A Retrospective Analysis
}

\author{
Darkhan Mami $^{1 \star}$, Mirzakarim Alchinbayev ${ }^{2}$, Alexander Kazachenko ${ }^{3}$
}

\begin{abstract}
${ }^{1}$ Scientific Center of Urology named after B.U. Jarbussynov, Almaty, KAZAKHSTAN
${ }^{2}$ The Asfendiyarov Kazakh National Medical University, Urology Department, Almaty, KAZAKHSTAN

${ }^{3} \mathrm{~N}$. Lopatkin Scientific Research Institute of Urology and Interventional Radiology, Moscow, RUSSIA *Corresponding Author: darhan.md@gmail.com
\end{abstract}

Citation: Mami D, Alchinbayev M, Kazachenko A. Comparison of Minimally Invasive Treatment Methods for Urinary Stones: A Retrospective Analysis. Electron J Gen Med. 2021;18(6):em321. https://doi.org/10.29333/ejgm/11252

\section{ARTICLE INFO}

Received: 21 Feb. 2021

Accepted: 5 Sep. 2021

\begin{abstract}
Introduction: Nephrolithiasis is one of the health concerns worldwide with the increasing prevalence and recurrence rates and the prevalence is ranging from 7\% to $13 \%$ in North America, 5-9\% in Europe, and 1-5\% in Asia. Urinary stones are affecting approximately $12 \%$ of the world population of all ages, sex, and race. In this study, we evaluate of efficacy of retrograde intrarenal surgery (RIRS) combined with percutaneous nephrolithotomy (PCNL) in the treatment of kidney stones and compare its results with RIRS and PCNL monotherapy.
\end{abstract}

Methods: We analyzed 144 patients who underwent combined method (12.5\%), RIRS (53.4\%), and PCNL (36.1\%) treatments between 2017 and 2018. The stone-free rates after one session at different treatments were following combined method (94.44\%), RIRS (83.78\%), and PCNL (78.85\%). The mean duration of operation was $58.88 \pm 13.12$ min in combined method, $55.94 \pm 26.50 \mathrm{~min}$ in the RIRS, and $67.01 \pm 29.39 \mathrm{~min}$ in the PCNL group ( $<<0.0277$ ). Duration of hospitalization, intraoperative blood loss, blood transfusion hematuria and complication in the postoperative period were also evaluated.

Results: We found that the combined method had a higher stone-free rate, shorter length of stay. This could partially be explained by the minimal invasiveness, less trauma and high stone-free, which result in the complete evacuation of stones and fast recovery. Notably, most of the large, rigid, and complex stones were treated with the combined method. Although the combined treatment is a safe and effective method, the complication rate was slightly higher.

Keywords: kidney stones, percutaneous nephrolithotomy, retrograde intrarenal surgery

\section{INTRODUCTION}

Nephrolithiasis (urolithiasis) is one of the health concerns worldwide with the increasing prevalence and recurrence rates and the prevalence is ranging from $7 \%$ to $13 \%$ in North America, 5-9\% in Europe, and 1-5\% in Asia [1,2]. Urinary stones are affecting approximately $12 \%$ of the world population of all ages, sex, and race [3]. It had been noted that the nephrolithiasis was mainly occurred in men than in women, however, this disparity of male to female ratio is declining recently [4]. In many countries of Asia, the prevalence of nephrolithiasis has significantly increased, for example in China from $4 \%$ to $6.4 \%$, Japan from $4.3 \%$ to $9.0 \%$, South Korea from $3.5 \%$ to $11.5 \%$, Thailand from $1.4 \%$ to $16.9 \%$ [5]. The worldwide significant prevalence of urinary stones drives researchers to constantly investigate its etiology and pathogenesis, look for effective prevention methods, improve diagnostic techniques, and introduce new technologies for medical and surgical treatments. With the development of modern minimally invasive technologies such as retrograde intrarenal surgery (RIRS), percutaneous nephrolithotomy (PCNL), and extracorporeal shock wave lithotripsy (ESWL) the significant changes have occurred in the surgical treatment of nephrolithiasis [6]. According to the current EAU Guidelines ESWL and RIRS are considered the first-choice treatment for renal stones $<2 \mathrm{~cm}$ and PCNL is the first-line treatment for renal stones $\geq 2 \mathrm{~cm}$ [7]. However, in cases of complex renal stones, PCNL alone approach has some limitations such as difficulty in percutaneous access, a necessity in multiple tracts, and migration of residual fragments to the ureter $[8,9]$. Similarly, although RIRS has made improvements in endourological devices there are still restraints in treating patients with large stones $\geq 2 \mathrm{~cm}$ demonstrating lower stone-free and high complication rates $[10,11]$. Simultaneous use of RIRS with PCNL at the same session has been a new treatment modality recently. Therefore, it is believed that the combined RIRS and PCNL approach would overcome the disadvantages of RIRS and PCNL monotherapies in urinary stones [12]. In this study, we compared RIRS combined with PCNL (combined), RIRS alone (RIRS), and PCNL alone (PCNL) treatments and hypothesized that the combined method would be more effective in treating urolithiasis compared to RIRS or PCNL in a single session. 


\section{MATERIALS AND METHODS}

\section{Study Design and Study Population}

This was a retrospective analysis of 144 patients who were treated for nephrolithiasis from December 2017 to December 2018 at the Scientific Center of Urology, Almaty city, Kazakhstan (which was the clinical setting and recruitment site). Kidney stones were identified by ultrasound and computer tomography (CT) examinations.

We included participants aged 18 years and older of both sexes with a single and/or multiple stones that required surgical management, completed lab and imaging data as well as providing informed consent. We excluded patients younger than 18 years old, patients, with severe comorbidities such as renal failure, history of previous pyelonephritis, preoperative diagnosis of a renal scar under, end-stage renal failure, or with acute renal failure (ARF), or any acute inflammatory process in the kidneys or urinary tract. The study was approved by the Local Ethical Committee (Institutional Review Board) of №13 (64).

\section{Operative Techniques}

According to the surgical procedure, the patients were divided into three groups. Surgical procedures were performed by the same certified and experienced medical specialist following the same protocol. The selection of the patients for the specific surgical technique was based on the stone size, density and localization. The selection for the specific treatment technique was decided by the physician and explained to the patient the reason of chosen treatment technique.

The RIRS group received retrograde intrarenal surgery, aimed at the stone destruction in the urinary tract through natural passage ways access without damaging the skin integrity. The procedure was performed under spinal anesthesia on supine position. A cystoscope No. 22, with $30^{\circ}$ optics, was inserted into the urethra. After stone visualization, the contact lithotripsy was performed. The cavity was drained by a stenting catheter (6/26); whereas the bladder was drained by a urethral catheter removed 1-2 days post-surgery.

PCNL group received percutaneous nephrolithotomy, a minimally invasive method for treating urolithiasis through direct endoscopic access into the kidney through an incision in the skin and removal of stone through this nephrostomy passage. PCNL was performed under spinal anesthesia (SMA) on prone position of the patient. After processing the operating field, the kidney was punctured under ultrasound and X-ray control for a contact lithotripter "Storz" or an ultrasonic lithotripter "Lithoclast master" (Switzerland) placement and stone removal. The kidney was drained by a nephrostomy tube (size of nephrostomy no. 12 or 14).

A combined group received RIRS in combination with PCNL that was performed under SMA anesthesia on the back of the patient starting with RIRS and then switching to PCNL as described above. The procedure was completed by drain the aging kidney with a nephrostomy tube (size of nephrostomy no. 12 or 14). In the case of a stone-free cavity, the antegrade catheter was inserted to drain the kidney.

Age, sex, BMI, stone size, stone location, stone side, surgery duration, stone-free rate, hospital stay duration, complication rate was analyzed. Stone free rate (SFR) was determined within a week after the surgery and was defined as the absence of stones or residual stone fragments more than $4 \mathrm{~mm}$ in size. The variables stone size, stone location and stone side were identified using ultrasound (LOGIQ S8 expert) and computer tomography (CT) (Toshiba aquilion 16) examinations. These examinations were done by the same certified and experienced medical specialist. The stone size was measured in millimeters and the stone was considered present if the stone size is $\geq 4 \mathrm{~mm}$. The stone location was defined as the identification of the stone in pelvis, calyx or ureter. The stone side was defined as the stone located in the right kidney, left kidney or both kidneys. The complication rate is defined as the number of complications divided by the number of patients. For the specific complication, we divided the number of a certain complication to the total number of the complications. In this study we used intra- and post- operative complication rates. Intraoperative complications, which are the complications during the surgery, include: hemorrhage, hematuria, kinked ureter/stent catheter, ureter stricture, perforation of the ureter. Postoperative complications, which are the complications after the surgery, include: exacerbation of pyelonephritis, percutaneous nephrostomy, endoscopic ureteral stricture bougienage, blood transfusion, ureteropyeloplasty, stent-catheter placement. Complete blood count, urine analysis, serum creatinine and urea of the patients were analyzed before and after the operation.

Alcohol consumption was defined as the act of ingesting typically orally - a beverage (may include: beer, wine, distilled spirits, and beverages that contain combinations of these or other additives, including malt liquor, fortified wine, liqueur, and cordials) containing ethanol and asked if the patients ever drunk, never drank or quit alcohol. Smoking is defined as the act of inhaling and exhaling the fumes of tobacco (cigarette, cigar or pipe) and is divided into three categories as never smoked, smoking and quit smoking. Diabetes is defined as a random glucose $\geq 11.1 \mathrm{mmol} / \mathrm{L}, \mathrm{HbA} 1 \mathrm{c} \geq 6.5 \%$ ( $\geq 48 \mathrm{mmol} / \mathrm{moL}$ ), self-reported use of diabetic medication, or history of physician-diagnosed diabetes. Hypertension is defined as systolic blood pressure $>=140$ or diastolic blood pressure $>=90$ $\mathrm{mmHg}$ or taking antihypertensive medication.

Statistical analysis was performed using SAS University Edition, version 3.8 (SAS Institute Inc., Cary, NC, USA.). Categorical variables were expressed as frequency and percent. We used the Chi-square test and Fisher's exact test to assess differences and associations between categorical variables. Continuous variables were expressed as mean and standard deviation (SD) and were analyzed using one-way analysis of variance. Kruskal-Wallis test was used for comparison of non-normally distributed continuous variables and presented as median (interquartile range). We used logistic regression to estimate crude and adjusted odds ratios (ORs) and $95 \%$ confidence intervals (Cls) for associations between potential risk factors and stone free rate, intra- and postoperative complications. The alpha level was setup at 0.05 considering it statistically significant.

\section{RESULTS}

A total of 144 patients with kidney stones were included in the study. Out of 144 patients, 77 (53.4\%) patients were in RIRS group, $52(36.1 \%)$ in PCNL group, $18(12.5 \%)$ in combined group. The mean age of patients was 47.6 (12.9) years old, and 
Table 1. Demographic characteristics and clinical data at baseline comparing RIRS, PCNL, and Combined groups

\begin{tabular}{|c|c|c|c|c|c|}
\hline Characteristics & $\operatorname{RIRS}^{1}(n=74)$ & $\mathrm{PCNL}^{2}(\mathrm{n}=52)$ & Combined $^{3}(n=18)$ & Total $(n=144)$ & $\mathbf{P}$ \\
\hline Age, years (mean \pm SD) & $48.68 \pm 13.72$ & $45.4 \pm 12.63$ & $49.61 \pm 8.86$ & $47.61 \pm 12.85$ & 0.2899 \\
\hline Age (\%) & & & & & 0.8418 \\
\hline$\geq 60$ & $17(22.97)$ & $10(19.23)$ & $3(16.67)$ & $30(20.83)$ & \\
\hline$<60$ & $57(77.03)$ & $42(80.77)$ & $15(83.33)$ & $114(79.17)$ & \\
\hline $\operatorname{Sex}(\%)$ & & & & & 0.1538 \\
\hline Male & 27 (36.49) & $28(53.85)$ & $8(44.44)$ & $63(43.75)$ & \\
\hline Female & $47(63.51)$ & $24(46.15)$ & $10(55.56)$ & $81(56.25)$ & \\
\hline $\mathrm{BMI}^{4}, \mathrm{~kg} / \mathrm{m}^{2}($ mean $\pm \mathrm{SD})$ & $24.6 \pm 4.11$ & $24.12 \pm 4.6$ & $25.5 \pm 3.42$ & $24.54 \pm 4.22$ & 0.3220 \\
\hline BMI (\%) & & & & & 0.6880 \\
\hline$\geq 25$ & $44(59.46)$ & $32(61.54)$ & $9(50)$ & 85 (59.03) & \\
\hline$<25$ & $30(40.54)$ & $20(38.46)$ & $9(50)$ & $59(40.97)$ & \\
\hline Alcohol (\%) & $16(21.62)$ & $14(26.92)$ & $4(22.22)$ & $34(23.61)$ & 0.7613 \\
\hline Smoking (\%) & $19(25.68)$ & $24(46.15)$ & $6(33.33)$ & $49(34.03)$ & 0.0576 \\
\hline Diabetes (\%) & $7(9.46)$ & $4(7.69)$ & $3(16.67)$ & $14(9.72)$ & 0.5667 \\
\hline Hypertension (\%) & $23(31.08)$ & $16(30.77)$ & $5(27.78)$ & $44(30.56)$ & 0.9626 \\
\hline Stone size mm, median (IQR & $14.65(5-71.5)$ & $23(8.5-79.5)$ & $12.5(2.75-36.5)$ & $17(2.75-79.5)$ & 0.0001 \\
\hline Stone side (\%) & & & & & 0.2697 \\
\hline Left side & $38(51.35)$ & 17 (32.69) & $8(44.44)$ & $63(43.75)$ & \\
\hline Right side & $24(32.43)$ & $26(50)$ & $8(44.44)$ & $58(40.28)$ & \\
\hline Both sides & $12(16.22)$ & $9(17.31)$ & $2(11.11)$ & $23(15.97)$ & \\
\hline \multicolumn{6}{|l|}{ Localization of the stone (\%) } \\
\hline Pelvis & $62(83.78)$ & $33(63.46)$ & $17(94.44)$ & $112(77.78)$ & 0.0052 \\
\hline Calyx & $25(33.78)$ & $33(63.46)$ & $7(38.89)$ & $65(45.14)$ & 0.0037 \\
\hline Ureter & $8(10.81)$ & $2(3.85)$ & $4(22.22)$ & $14(9.72)$ & 0.0062 \\
\hline
\end{tabular}

${ }^{1} \mathrm{RIRS}$ - retrograde intrarenal surgery; ${ }^{2} \mathrm{PCNL}$ - percutaneous nephrolithotomy; ${ }^{3}$ Combined - RIRS+PCNL; ${ }^{4} \mathrm{BMI}$ - body mass index; ${ }^{5} \mathrm{QRR}$ - inter quartile range

$56.3 \%$ were females. The groups did not differ in terms of age, sex, stone side, BMI, alcohol consumption, smoking status, diabetes, and hypertension status. The median stone size was 17 (IQR: 2.75 - 79.5) $\mathrm{mm}$ and it was significantly different among groups ( $p=0.0001$ ). After conducting post hoc using Bonferroni test, RIRS and PCNL groups were statistically different $(p<.0001)$ as well as PCNL and combined groups $(p=0.0024)$, however there was no difference between RIRS and Combined groups $(p=0.8452)$. The stones were almost equally located in the right $(40.28 \%)$ and left kidney $(43.75 \%)$ and there was no significant difference among groups $(p=0.2697)$. The stones were mostly localized in the kidney pelvis and the difference among groups was statistically significant $(p=0.0052)$ (Table 1).

Most of the intra- and postoperative complications have occurred in the combined group. A blood transfusion was required in 2 cases (3.85\%). Hematuria was the only intraoperative complication in the PCNL group accounting for $19.23 \%$ of cases. Two cases of hemorrhage $(11.11 \%)$, two cases of the stricture $(11.11 \%)$, and one case of ureter perforation $(5.56 \%)$ have occurred in the combined group. Exacerbation of pyelonephritis was the most frequent postoperative complication in the RIRS (6.76\%) and the PCNL (17.31\%) groups. The operation time of the combined group $(58.88 \pm 13.12 \mathrm{~min})$ was shorter than those in the PCNL group $(67.01 \pm 29.39 \mathrm{~min})$ but longer than those in the RIRS group $(55.94 \pm 26.5 \mathrm{~min})(p=0.0277)$. The median length of stay of the combined group was lower (7 (6-10)) than those in the PCNL group (8(5-16)) but it was the same with the RIRS group (7 (515)) $(p=0.0001)$. However, after conducting post hoc using Bonferroni test, only RIRS and PCNL groups were statistically different $(p<.0007)$. The stone-free rate within one-week postsurgery was higher in the combined group $(94.44 \%)$ than in RIRS (83.78) and PCNL (78.85) groups $(p=0.0178)$. Residual stones were mostly appeared in RIRS and PCNL groups than in the combined group ( $p=0.0178$ ) (Table 2).

Renal damage was assessed by looking at creatinine, urea levels before and after operation and differences among groups were not statistically significant $(p>.05)$ as shown in Table 3. Hemoglobin $(\mathrm{Hb})$ was slightly reduced after the operation, however this finding was not statistically significant $(p>.05)$. Differences of urine red blood cells (RBC) and blood white blood cells (WBC) among groups before and after operation were not statistically significant $(p>.05)$, but urine

Table 2. Intra- and postoperative clinical data comparing RIRS, PCNL, and Combined groups

\begin{tabular}{|c|c|c|c|c|c|}
\hline Characteristics & $\operatorname{RIRS}^{1}(n=74)$ & $\mathrm{PCNL}^{2}(\mathrm{n}=52)$ & Combined $^{3}(n=18)$ & Total $(n=144)$ & $\mathbf{P}$ \\
\hline Operating time min, (mean $\pm S D)$ & $55.94 \pm 26.50$ & $67.01 \pm 29.39$ & $58.88 \pm 13.12$ & $60.31 \pm 26.71$ & 0.0277 \\
\hline Hospital stay, days median (IQR $\left.{ }^{4}\right)$ & $7(5-15)$ & $8(5-16)$ & $7(6-10)$ & $7(5-16)$ & 0.0001 \\
\hline \multicolumn{6}{|l|}{ Stone-free rate within 1 week (\%) } \\
\hline Stone free & $62(83.78)$ & $41(78.85)$ & $17(94.44)$ & $120(83.33)$ & 0.0178 \\
\hline Residual stone & $12(16.22)$ & $11(21.15)$ & $1(5.56)$ & $24(16.67)$ & 0.0178 \\
\hline \multicolumn{6}{|l|}{ Intraoperative complications (\%) } \\
\hline Absent & 71 (95.95) & $42(80.77)$ & $13(72.22)$ & $126(87.5)$ & 0.0001 \\
\hline Hemorrhage & 0 & 0 & $2(11.11)$ & $2(1.39)$ & \\
\hline Hematuria & 0 & $10(19.23)$ & 0 & $10(6.94)$ & \\
\hline Kinked ureter, stent catheter & $2(2.7)$ & 0 & 0 & $2(1.39)$ & \\
\hline Ureter stricture & $1(1.35)$ & 0 & $2(11.11)$ & $3(2.08)$ & \\
\hline Perforation of the ureter & 0 & 0 & $1(5.56)$ & $1(0.69)$ & \\
\hline
\end{tabular}

${ }^{1} \mathrm{RIRS}$ - retrograde intrarenal surgery; ${ }^{2} \mathrm{PCNL}$ - percutaneous nephrolithotomy; ${ }^{3}$ Combined - RIRS+PCNL; ${ }^{4} \mathrm{IQR}$ - inter quartile range 
Table 2 (continued). Intra- and postoperative clinical data comparing RIRS, PCNL, and Combined groups

\begin{tabular}{|c|c|c|c|c|c|}
\hline Characteristics & $\operatorname{RIRS}^{1}(n=74)$ & $\mathrm{PCNL}^{2}(\mathrm{n}=52)$ & Combined $^{3}(n=18)$ & Total $(n=144)$ & $\mathbf{P}$ \\
\hline \multicolumn{6}{|l|}{ Postoperative complications (\%) } \\
\hline Absent & $66(89.19)$ & $41(78.85)$ & $13(72.22)$ & $120(83.33)$ & 0.0010 \\
\hline Exacerbation of pyelonephritis & $5(6.76)$ & $9(17.31)$ & 0 & $14(9.72)$ & \\
\hline Percutaneous nephrostomy & 0 & 0 & $2(11.11)$ & $2(1.39)$ & \\
\hline Endoscopic ureteral stricture bougienage & $2(2.7)$ & 0 & $1(5.56)$ & $3(2.08)$ & \\
\hline Blood transfusion & 0 & $2(3.85)$ & 0 & $2(1.39)$ & \\
\hline Ureteropyeloplasty & $1(1.35)$ & 0 & $1(5.56)$ & $2(1.39)$ & \\
\hline Stent-catheter placement & 0 & 0 & $1(5.56)$ & $1(0.69)$ & \\
\hline
\end{tabular}

Table 3. Pre and postoperative blood and urine assessment

\begin{tabular}{|c|c|c|c|c|}
\hline Characteristics & $\operatorname{RIRS}^{1}(n=74)$ & $\mathrm{PCNL}^{2}(\mathrm{n}=52)$ & Combined $^{3}(n=18)$ & $\mathbf{P}$ \\
\hline \multicolumn{5}{|l|}{ Preoperative } \\
\hline Creatinine & $73.65(36-144)$ & $78(45-97.75)$ & $77.2(48-117)$ & 0.7074 \\
\hline Urea & $5.11(1.2-13.7)$ & $4.9(3.1-10.4)$ & $4.95(2.2-8.4)$ & 0.5454 \\
\hline $\mathrm{Hb}^{4}$ & $134.08 \pm 16.64$ & $133.42 \pm 17.86$ & $131.89 \pm 18.4$ & 0.8878 \\
\hline $\mathrm{WBC}^{5}$ (blood) & $6.9(3.4-15.3)$ & $6.65(3.5-11.9)$ & $7.1(4.1-9.6)$ & 0.5993 \\
\hline $\mathrm{RBC}^{6}$ (urine) & $3(0-35)$ & $2(0-50)$ & $2(0-8)$ & 0.2123 \\
\hline WBC (urine) & $8(0-64)$ & $3.5(0-30)$ & $8(2-60)$ & 0.2327 \\
\hline \multicolumn{5}{|l|}{ Postopertive } \\
\hline Creatinine & $75(26-109)$ & $76.5(39-111)$ & $73.5(7.4-131)$ & 0.5485 \\
\hline Urea & $4.48(2.22-8.80)$ & $4.4(2.4-9.5)$ & $4.87(2.34-7.1)$ & 0.7113 \\
\hline $\mathrm{Hb}$ & $130.16 \pm 17.67$ & $122.6 \pm 20.8$ & $126 \pm 20.75$ & 0.0969 \\
\hline WBC (blood) & $7.5(4.5-15.5)$ & $7.35(4.5-12.5)$ & $8.05(4.4-15.5)$ & 0.1762 \\
\hline RBC (urine) & $9(1-65)$ & $4.5(0-65)$ & $4(0-58)$ & 0.0621 \\
\hline WBC (urine) & $9(1-70)$ & $8(0-60)$ & $21.5(1-58)$ & 0.0298 \\
\hline
\end{tabular}

${ }^{1} \mathrm{RIRS}$ - retrograde intrarenal surgery; ${ }^{2} \mathrm{PCNL}$ - percutaneous nephrolithotomy; ${ }^{3}$ Combined - RIRS+PCNL; ${ }^{4} \mathrm{Hb}$ : hemoglobin; ${ }^{5} \mathrm{WBC}$ : white blood cells; ${ }^{6} \mathrm{RBC}$ : red blood cells; the results were shown as median (range) and mean \pm standard deviation where appropriate.

Table 4. Outcome assessment between groups (RIRS, PCNL and Combined), multivariate analysis

\begin{tabular}{|c|c|c|c|c|c|c|}
\hline & \multicolumn{2}{|c|}{ Stone free rate } & \multicolumn{2}{|c|}{$\begin{array}{l}\text { Intraoperative } \\
\text { Complications }\end{array}$} & \multicolumn{2}{|c|}{$\begin{array}{l}\text { Postoperative } \\
\text { Complication }\end{array}$} \\
\hline & $\begin{array}{l}\text { Crude }{ }^{1} \mathrm{OR} \\
\left(95 \%{ }^{2} \mathrm{Cl}\right)\end{array}$ & $\begin{array}{c}\text { Adjusted OR } \\
(95 \% \mathrm{Cl})^{\star}\end{array}$ & $\begin{array}{l}\text { Crude OR } \\
(95 \% \mathrm{CI})\end{array}$ & $\begin{array}{c}\text { Adjusted OR } \\
(95 \% \mathrm{Cl})^{\star}\end{array}$ & $\begin{array}{l}\text { Crude OR } \\
(95 \% \mathrm{Cl})\end{array}$ & $\begin{array}{c}\text { Adjusted OR } \\
(95 \% \mathrm{Cl})^{\star}\end{array}$ \\
\hline $\begin{array}{c}{ }^{3} \text { RIRS vs } \\
{ }^{5} \text { Combined }\end{array}$ & $1.4(0.3-6.9)$ & $1.4(0.3-7.1)$ & $0.1(0.02-0.5)$ & $0.1(0.02-0.5)$ & $0.3(0.1-1.1)$ & $0.3(0.1-1)$ \\
\hline $\begin{array}{l}{ }^{4} \mathrm{PCNL} \text { vs } \\
\text { Conmined }\end{array}$ & $2.1(0.4-10.8)$ & $2.3(0.4-12.1)$ & $0.6(0.2-2.1)$ & $0.4(0.1-1.6)$ & $0.7(0.2-2.4)$ & $0.4(0.1-1.7)$ \\
\hline
\end{tabular}

${ }^{\star}$ Adjusted for age, gender, BMI and stone size; $\mathrm{OR}^{1}$ : odds ratio; $\mathrm{Cl}^{2}$ : confidence intervals ${ }^{3} \mathrm{RIRS}$ - retrograde intrarenal surgery; ${ }^{4} \mathrm{PCNL}$ - percutaneous nephrolithotomy; ${ }^{5}$ Combined - RIRS+PCNL; Combined group was the reference group

WBC had significantly increased after the operation ( $p=0.0298)$. (Table 3).

The odds of stone free rate were 1.4 times higher in RIRS group compared to Combined group and 2.3 times higher in PCNL group compared to combined group after adjustment for age, gender, BMI and stone size, however these findings were not statistically significant, $\mathrm{Cls}$ 0.3-7.1 and 0.4-12.1, respectively. The odds of intraoperative complications were 0.1 times lower in RIRS group compared to combined group after adjustment for age, gender, BMI and stone size and it was statistically significant $(\mathrm{Cl}, 0.02-0.5)$. The odds of intraoperative complications were 0.4 times lower in PCNL group compared to combined group, and it was not statistically significant $(\mathrm{Cl}$, 0.1-1.6). The comparison of postoperative complications between groups was not statistically significant (RIRS vs Combined 0.3 (0.1-1), PCNL vs Combined 0.4 (0.1-1.7)) (Table 4).

\section{DISCUSSION}

This study demonstrates a comparative analysis of the outcomes of RIRS combined with PCNL (combined), RIRS alone
(RIRS), and PCNL alone (PCNL) methods in the treatment of kidney stone disease. We found that the combined method had a higher stone-free rate, shorter length of stay but with a slightly higher minor complication rate than in RIRS or PCNL groups, however after adjusting for age, gender and BMI the results were not statistically significant. The main goal in treating urinary stones is obtaining a higher stone-free rate with less morbidity to improve patients' quality of life. The size, site, localization of the stones, features of the urinary tract, comorbidities, age, sex, BMI are important factors for the treatment tactics and planning of nephrolithiasis [13]. Kidney stone management has been changed since the advancement of endoscopic technology.

Some studies have shown that the combined treatment method of RIRS with PCNL had higher SFR than the PCNL alone treatment in a single session [14]. However, in our study we did not find statistically significant result as it was shown previously. One reason could be because most of the large, rigid, and complex stones were treated with the combined method. On the other hand, the stone size of less than $3 \mathrm{~cm}$ was mostly treated by the RIRS, and the large stones $(>3 \mathrm{~cm})$ were mainly treated with the PCNL method. Furthermore, the combined method was mainly used in complex, upper, and 
middle calyceal stones. The EAU Guideline [7] states that there might be over-treatment caused due to false-positive imaging tests. We performed imaging in the first-week post-surgery, but the follow-up imaging is also recommended at four weeks post-surgery to reduce false-positive results.

Although the postoperative complication rate was higher in the combined group, these complications were minor as seen in the previous studies [15]. Besides, the patients with a stone size of more than $5 \mathrm{~cm}$ had the most complications. Two patients in the combined group had hemorrhaged and both of them required the blood transfusion. The reasons for this complication could be the stone size and access sheath size as these were noted in previous studies [16-18].

The total operative time in the combined group was reasonable as in RIRS and PCNL groups. Several factors have been stated in the literature on the impact of operative time during urological surgery $[15,19,20]$. One factor that increased the operative time might be time for blood transfusion [19], which was the case in the combined group. Another factor that could shorten the operative time might be the surgical technique and experience of the surgeon as well as patients' position during the surgery $[15,19]$. Moreover, in some other studies combined method demonstrated shorter operative time and it is possibly due to the variation in patient populations and different techniques used [20]. In our study, although patients who underwent the combined methods had more complex cases, we did not see significant results in the operative time among treatment groups. The length of stay was shorter in the combined group compared to PCNL group, however the combined and RIRS groups had the same length of stay. This could partially be explained by the minimal invasiveness, less trauma and high stone-free rate, which result in the complete evacuation of stones and fast recovery. The differences of creatinine, urea, hemoglobin and white blood cells counts in the blood were not statistically significant before and after operation among three groups, which was the indication that patients endured operations well. However, WBC count in the urine has increased after the operation and the difference was statistically significant among groups. This difference could have occurred because of the postoperative complication such as exacerbation of pyelonephritis. After adjustment for age, gender and BMI, the RIRS group had less intraoperative complications than the combined group. This finding could be explained by the small sample size and allocating patients with serious conditions in combined group.

There were some limitations associated with the current study. This was a retrospective study where bias and confounding factors may have arisen due to the inherent study design limitations. Another limitation is in small sample size and follow-up time post-surgery that could limit the comparison only for in-hospital and short-term outcomes. We were not able to invite patients for follow-up visits to our Center due to the geographical distance that patients had to travel for check-ups. However, we share our contact information to be notified in case the patient faces any health event. The major limitation was the potential presence of selection bias. We did not collect additional information (for example, history of kidney disease, other comorbidities, duration of the disease) to determine whether distributions of severe cases were equally among the three groups. Next, this was a single-center study which results could be generalized only for the Center's experience. Since the Scientific Center admits patients across the country with complex and severe cases, we should also study patients who get treatment in regional hospitals of the country. We should study more patients and look at the long-term outcomes to see the true difference between treatments.

\section{CONCLUSIONS}

In terms of stone free rate and complication rates there was no difference among treatment groups. However, it is worth to admit that the combined group was assigned to more severe cases thus complications were likely occur, and residual stones were likely detected after an operation.

Main points:

1. Combined treatment was mainly used in patients with complex, upper, and middle calyceal stones. Moreover, small $(<3 \mathrm{~cm})$ and large $(>3 \mathrm{~cm})$ stones were mostly treated by RIRS and PCNL methods, respectively.

2. The hospital stay was shorter in the combined group compared to PCNL group, however it was the same between combined and RIRS groups.

3. The complication rate was slightly higher in the combined group. However, the complications were not severe and proceeded more favorably.

Author contributions: All authors have sufficiently contributed to the study, and agreed with the results and conclusions.

Funding: No funding source is reported for this study.

Declaration of interest: No conflict of interest is declared by authors.

\section{REFERENCES}

1. Romero V, Akpinar H, G. Assimos D. Kidney Stones: A Global Picture of Prevalence, Incidence, and Associated Risk Factors. Rev Urol. 2010;12(2-3):86-96. https://doi.org/ 10.3909/riu0459

2. Sorokin I, Mamoulakis C, Miyazawa K, Rodgers A, Talati J, Lotan Y. Epidemiology of stone disease across the world. World J Urol. 2017;35(9):1301-20. https://doi.org/10.1007/ s00345-017-2008-6 PMid:28213860

3. Alelign T, Petros B. Kidney Stone Disease: An Update on Current Concepts. Adv Urol. 2018;2018:1-12. https://doi.org/10.1155/2018/3068365 PMid:29515627 PMCid:PMC5817324

4. Bae SR, Seong JM, Kim LY, Paick SH, Kim HG, Lho YS, Park HK. The epidemiology of reno-ureteral stone disease in Koreans: a nationwide population-based study. Urolithiasis. $2014 \quad$ apr $1 ; 42(2): 109-14$. https://doi.org/10.1007/s00240-014-0643-6 PMid:24526235

5. Liu Y, Chen Y, Liao B et al. Epidemiology of urolithiasis in Asia. Asian J Urol. 2018;5(4):205-214. https://doi.org/ 10.1016/j.ajur.2018.08.007 PMid:30364478 PMCid: PMC6197415

6. Karakoc O, Karakeci A, Ozan T et al. Comparison of retrograde intrarenal surgery and percutaneous nephrolithotomy for the treatment of renal stones greater than $2 \mathrm{~cm}$. Türk Üroloji Dergisi/Turkish Journal of Urology. 2015;41(2):73-77. https://doi.org/10.5152/tud.2015.97957 PMid:26328205 PMCid:PMC4548665 
7. European Association Urology. European Association of Urology Guidelines. 2020 Edition.; European Association of Urology Guidelines Office, Ed.; European Association of Urology Guidelines Office: Arnhem, The Netherlands, 2020; Vol. presented.

8. Sabler I, Katafigiotis I, Gofrit O, Duvdevani M. Present indications and techniques of percutaneous nephrolithotomy: What the future holds? Asian J Urol. 2018;5(4):287-94. https://doi.org/10.1016/j.ajur.2018.08. 004 PMid:30364501 PMCid:PMC6197369

9. Zhou M, He X, Zhang Y, Yu W. Optical puncture combined with balloon dilation PCNL vs. conventional puncture dilation PCNL for kidney stones without hydronephrosis: a retrospective study. BMC Urol. 2019;19(1):122. https://doi.org/10.1186/s12894-019-0558-1 PMid:31775711 PMCid:PMC6882241

10. Kang S, Cho K, Kang D, Jung H, Kwon J, Lee J. Systematic review and meta-analysis to compare success rates of retrograde intrarenal surgery versus percutaneous nephrolithotomy for renal stones $>2 \mathrm{~cm}$. Medicine (Baltimore). 2017;96(49):e9119. https://doi.org/10.1097/ md.0000000000009119 PMid:29245347 PMCid: PMC5728962

11. Kilic O, Akand M, Van Cleynenbreugel B. Retrograde intrarenal surgery for renal stones - Part 2. Türk Üroloji Dergisi/Turkish Journal of Urology. 2017;43(3):252-60. https://doi.org/10.5152/tud.2017.22697 PMid:28861294 PMCid:PMC5562241

12. Scoffone C, Cracco C. Invited review: the tale of ECIRS (Endoscopic Combined IntraRenal Surgery) in the Galdakao-modified supine Valdivia position. Urolithiasis. 2017;46(1):115-23. https://doi.org/10.1007/s00240-0171015-9 PMid:29189885

13. Assimos D, Krambeck A, Miller N et al. Surgical Management of Stones: American Urological Association/Endourological Society Guideline, PART I. Journal of Urology. 2016;196(4):1153-60. https://doi.org/10.1016/j.juro.2016. 05.090 PMid:27238616
14. Hamamoto S, Yasui T, Okada A et al. Endoscopic Combined Intrarenal Surgery for Large Calculi: Simultaneous Use of Flexible Ureteroscopy and Mini-Percutaneous Nephrolithotomy Overcomes the Disadvantageous of Percutaneous Nephrolithotomy Monotherapy. J Endourol. 2014;28(1):28-33. https://doi.org/10.1089/end.2013.0361 PMid:23987470

15. Gao H, Zhang H, Wang Y et al. Treatment of Complex Renal Calculi by Digital Flexible Ureterorenoscopy Combined with Single-Tract Super-Mini Percutaneous Nephrolithotomy in Prone Position: A Retrospective Cohort Study. Medical Science Monitor. 2019;25:5878-85. https://doi.org/10.12659/msm.915034 PMid:31389405 PMCid:PMC6693367

16. Zeng G, Zhang T, Agrawal M et al. Super-mini percutaneous nephrolithotomy (SMP) vs retrograde intrarenal surgery for the treatment of $1-2 \mathrm{~cm}$ lower-pole renal calculi: an international multicentre randomised controlled trial. BJU Int. 2018;122(6):1034-40. https://doi.org/10.1111/bju. 14427 PMid:29873874

17. Meng X, Bao J, Mi Q, Fang S. The Analysis of Risk Factors for Hemorrhage Associated with Minimally Invasive Percutaneous Nephrolithotomy. Biomed Res Int. 2019;2019:1-6. https://doi.org/10.1155/2019/8619460 PMid:30834279 PMCid:PMC6374806

18. Ganpule A, Vijayakumar M, Malpani A, Desai M. Percutaneous nephrolithotomy (PCNL) a critical review. International Journal of Surgery. 2016;36:660-4. https://doi.org/10.1016/j.ijsu.2016.11.028 PMid:27856356

19. Jiao B, Lai S, Xu X, Zhang M, Diao T, Zhang G. The efficacy of flexible ureteroscopy lithotripsy and miniaturized percutaneous nephrolithotomy for the treatment of renal and proximal ureteral calculi of $\leqslant 2 \mathrm{~cm}$. Medicine (Baltimore). 2019;98(11):e14535. https://doi.org/10.1097/ md.0000000000014535 PMid:30882621 PMCid: PMC6426591

20. Mishra D, Agrawal M. Use of a Novel Flexible Mininephroscope in Minimally Invasive Percutaneous Nephrolithotomy. Urology. 2017;103:59-62. https://doi.org /10.1016/j.urology.2017.01.009 PMid:28104420 